\title{
Rare case of Streptococcal enteritis in HIV patient
}

\author{
Christina Kotsogianni, Zois I. Panos \\ Department of Internal Medicine, Attikon University Hospital of Athens, Greece
}

\begin{abstract}
Only a small number of cases of Streptococcus pneumoniae bacteremia with gastrointestinal tract involvement have been reported in the literature, even in immunocompromised patients.

This case report describes an immunosuppressed forty-year old human immunodeficiency virus (HIV)-positive patient with S. pneumoniae bacteremia presenting as acute enteritis. The patient suffered from fever, severe watery diarrhea, and acute abdomen. Laboratory tests showed elevation of inflammatory markers and acute kidney injury. Stool examination was positive for fecal leucocytes, while radiology studies were indicative of respiratory involvement. The patient was rehydrated and initially treated with IV ciproflocaxin and metronidazole, but after positive blood culture result for S. pneumoniae, the treatment was changed to IV ceftriaxone. The patient responded to the treatment and was discharged on $7^{\text {th }}$ day with oral moxifloxacin prescribed. Ten days after finishing the treatment, there was a lower respiratory tract recurrence with negative blood cultures for S. pneumoniae, which responded to meropenem without another recurrence until today.

In the last 26 years (1993-2019), a few cases have been described, two of which in HIV-positive patients. To our knowledge, this is the first case of concurrent severe $S$. pneumoniae pneumonia and enteritis without any complaints from the respiratory system in a severely immunosuppressed patient.
\end{abstract}

HIV AIDS Rev 2020; 19, 4: 284-288

DOI: https://doi.org/10.5114/hivar.2020.101796

Key words: HIV, immunosuppression, diarrhea, enteritis, Streptococcus pneumoniae.

\section{Introduction}

Streptococcus pneumoniae bacteremia involving the gastrointestinal tract is rarely reported in literature, even in immunosuppressed patients. In the last 26 years (1993-2019), a few cases have been described, two of which in human immunodeficiency virus (HIV)-positive patients (Table 1). In this case report, we describe a severely immunocompromised HIV-positive patient with $S$. pneumoniae bacteremia presenting as acute enteritis. Moreover, we present a review of the literature.

\section{Case presentation}

A severely immunocompromised forty-year-old HIVpositive male presented with fever, severe watery diarrhea ( $>6$ bowel movements per day), and diffuse abdominal pain without vomiting for three days. He was a heavy smoker with chronic pulmonary disease and a former intravenous drug user diagnosed with HIV five years ago, and complicated in the past with mycobacterium avium complex disease. He was under antiretroviral treatment with raltegravir, emtricitabine, and tenofovir disoproxil fumarate, with poor

Article history:

Received: 19.08.2019

Received in revised form: 28.04.2020

Accepted: 03.05.2020

Available online: 10.12 .2020
International Journal of HIV-Related Problems

HIV \& AIDS R e vi e w 
Table 1. Cases of pneumococcal enteritis reported between 1993-2018

\begin{tabular}{|c|c|c|c|c|c|c|}
\hline $\begin{array}{l}\text { Author(s), year } \\
\text { of publication }\end{array}$ & $\begin{array}{c}\text { Age } \\
\text { (years) }\end{array}$ & Site of infection & $\begin{array}{c}\text { Evidence } \\
\text { of } S . \text { pneumoniae }\end{array}$ & $\begin{array}{l}\text { Radiologic } \\
\text { findings }\end{array}$ & Treatment & $\begin{array}{l}\text { Predisposing } \\
\text { factors }\end{array}$ \\
\hline Argemi et al., 2016 & 35 & Appendix & Blood culture & $\begin{array}{c}\text { CT: dilated, thick- } \\
\text { walled, blind- } \\
\text { ending tubular } \\
\text { structure with } \\
\text { an } 8 \mathrm{~mm} \text { diameter }\end{array}$ & $\begin{array}{l}\text { Surgery, } \\
\text { antibiotics }\end{array}$ & - \\
\hline Caiero et al., 2015 & 43 & Appendix & $\begin{array}{l}\text { Culture of drained } \\
\text { purulent secretions }\end{array}$ & $\begin{array}{l}\text { CT: thickened } \\
\text { appendix (filled } \\
\text { with liquid) }\end{array}$ & $\begin{array}{l}\text { Surgery, } \\
\text { antibiotics }\end{array}$ & $\begin{array}{c}\mathrm{HIV+} \\
(\mathrm{CD} 4+239 \text { cells } / \mu \mathrm{l})\end{array}$ \\
\hline Clark et al., 1993 & 28 & Appendix & $\begin{array}{l}\text { Intraoperative } \\
\text { cultures }\end{array}$ & $\begin{array}{l}\text { US: free fluid in } \\
\text { the abdomen }\end{array}$ & $\begin{array}{l}\text { Surgery, } \\
\text { antibiotics }\end{array}$ & $\begin{array}{c}\text { HIV+ } \\
(\text { CD4+ } 390 \text { cells } / \mu l), \\
\text { hemophilia A }\end{array}$ \\
\hline Petti et al., 2002 & 33 & Terminal ileum & Blood culture & $\begin{array}{l}\text { CT: thickening } \\
\text { of the cecal wall }\end{array}$ & $\begin{array}{c}\text { Surgery, } \\
\text { antibiotics }\end{array}$ & - \\
\hline & 29 & Cecum & Swab of cecal wall & - & Surgery & - \\
\hline \multirow{4}{*}{$\begin{array}{l}\text { Ronnachit et al., } \\
2017\end{array}$} & 37 & $\begin{array}{c}\text { Peritoneum } \\
\text { fallopian tube }\end{array}$ & $\begin{array}{l}\text { Blood culture, } \\
\text { pelvic pus } P C R \text {, } \\
\text { urine } \mathrm{Ag}, \\
\text { ascites } \mathrm{Ag}\end{array}$ & - & $\begin{array}{l}\text { Surgery, } \\
\text { antibiotics }\end{array}$ & SLE, orogonitis \\
\hline & 40 & $\begin{array}{c}\text { Sigmoid colon, } \\
\text { lungs }\end{array}$ & Blood culture & - & Antibiotics & ITP \\
\hline & 41 & $\begin{array}{l}\text { Gastrointestinal } \\
\text { peritoneum }\end{array}$ & $\begin{array}{l}\text { Blood culture, } \\
\text { urine A, blood Ag, } \\
\text { stool Ag, } \\
\text { ascites Ag, } \\
\text { stool microscopy }\end{array}$ & - & $\begin{array}{l}\text { Antibiotics, } \\
\text { drainage }\end{array}$ & - \\
\hline & 49 & Gastrointestinal & $\begin{array}{c}\text { Blood culture, } \\
\text { urine } \mathrm{Ag} \text {, stool } \mathrm{Ag}\end{array}$ & - & Antibiotics & - \\
\hline Soman et al., 2009 & 77 & Gastrointestinal & Blood culture & - & Antibiotics & - \\
\hline
\end{tabular}

CT - computed tomography, DM - diabetes mellitus, ITP - idiopathic thrombocytopenia, IUCD - intrauterine contraceptive device, PID - pneumococcal invasive disease, SLE - systemic lupus erythematosus, US - ultrasound

compliance and last CD4 count of 15 cells $/ \mathrm{mm}^{3}$. On admission, he was in mild distress due to abdominal pain and high fever. He did not report other symptoms, such as headache, dyspnea, cough, or chest pain. Clinical examination indicated dehydration (tachycardia, mean blood pressure of $70 \mathrm{~mm} \mathrm{Hg}$, dry mucous membranes), revealing abdominal guarding and rebound tenderness with hypoactive bowel sounds. Obturator and psoas signs were negative. Lung auscultation showed scarce crackles and wheezing bilaterally without hypoxemia. Laboratory tests resulted in elevation of white blood cell count, C-reactive protein, urea, and creatine, as shown in Table 2. Normochromic normocytic anemia and thrombocytopenia were preexisting and attributed to severe acquired immunodeficiency syndrome (AIDS) disease. The quick sequential organ failure assessment (qSOFA) score indicated zero, while the sequential organ failure assessment (SOFA) score was regarded as inaccurate, since the patient's only pathological value was thrombocytopenia, which was a chronic finding. Further investigation with chest and abdominal X-rays identified a hazy infiltration in the left lower lobe and dilatation of bowel loops. In the meantime, stool examination was positive for fecal leucocytes. Rigorous intravenous rehydration and empirical combination of ciprofloxacin and metronidazole were initiated. Due to the severity of clinical symptoms, an abdominal and chest computed tomography $(\mathrm{CT})$ scanning were performed, revealing mild thickness of terminal ileum wall (the finding consistent with acute enteritis) and bilateral consolidation in the lower lobe with ground glass in the middle and upper left lobe, respectively. During the next two days, the patient's clinical condition quickly ameliorated with recession of his symptoms. On the third hospital day, penicillin sensitive S. pneumoniae was isolated from the blood culture drown on admission day and antibiotic treatment was switched to ceftriaxone. On the other hand, the stool culture for common enteropathogens (Salmonella, Shigella, Campylobacter, Vibrio, and Yersinia) and testing for Clostridium difficile (antigen and toxin) remained negative. Additionally, serology and PCR testing for CMV, HSV-1, HSV-2, and blood-sputum cultures for Mycobacterium tuberculosis were negative. The patient was 
Table 2. Laboratory tests values

\begin{tabular}{l|c|c}
\hline Laboratory test & Values & Normal range \\
\hline Hemoglobin (Hb) & $11.8 \mathrm{mg} / \mathrm{dl}$ & $13-17 \mathrm{mg} / \mathrm{dl}$ \\
\hline Hematocrit (HCT) & $33.6 \%$ & $40-52 \%$ \\
\hline Mean corpuscular volume (MCV) & $92.6 \mathrm{fl}$ & $80-100 \mathrm{fl}$ \\
\hline White blood cells (WBC) & $8.73 \times 10^{9} / \mathrm{l}$ & $4-10 \times 10^{9} / \mathrm{l}$ \\
\hline Neutrophils (PMN) & $94.8 \%$ & $40-80 \%$ \\
\hline Platelets (Plt) & $59 \times 10^{9} / \mathrm{l}$ & $150-400 \times 10^{9} / \mathrm{l}$ \\
\hline Glucose (Glu) & $87 \mathrm{mg} / \mathrm{dl}$ & $65-110 \mathrm{mg} / \mathrm{dl}$ \\
\hline Urea (Ur) & $116 \mathrm{mg} / \mathrm{dl}$ & $17-43 \mathrm{mg} / \mathrm{dl}$ \\
\hline Creatinine (Cr) & $1.9 \mathrm{mg} / \mathrm{dl}$ & $0.8-1.3 \mathrm{mg} / \mathrm{dl}$ \\
\hline Aspartate aminotransferase (AST) & $36 \mathrm{IU} / \mathrm{I}-30 \mathrm{U} / \mathrm{l}$ \\
\hline Alanine aminotransferase (ALT) & $20 \mathrm{IU} / \mathrm{l}$ & $5-30 \mathrm{U} / \mathrm{l}$ \\
\hline C-reactive protein (CRP) & $276 \mathrm{mg} / \mathrm{l}$ & $<5 \mathrm{mg} / \mathrm{l}$ \\
\hline Gamma glutamyl transferase $(\gamma G T)$ & $14 \mathrm{IU} / \mathrm{l}$ & $6-50 \mathrm{U} / \mathrm{l}$ \\
\hline Alkaline phosphatase (ALP) & $43 \mathrm{IU} / \mathrm{l}$ & $50-100 \mathrm{U} / \mathrm{l}$ \\
\hline Lactate dehydrogenase (LDH) & $333 \mathrm{IU} / \mathrm{l}$ & $50-150 \mathrm{U} / \mathrm{l}$ \\
\hline Creatine kinase (CK) & $947 \mathrm{IU} / \mathrm{l}$ & $25-200 \mathrm{U} / \mathrm{l}$ \\
\hline
\end{tabular}

discharged on the $7^{\text {th }}$ hospital day, with a recommendation to take moxifloxacin orally for a total of fourteen days. Ten days after the end of antibiotic treatment, there was a recurrence of fever accompanied with severe pain in right hemithorax, worsening in deep inspiration, and the patient was re-admitted to the hospital. No pathological findings, either from physical examination or chest X-ray, were observed. Meropenem was administered empirically due to the recent use of third generation cephalosporin. Another chest CT-scanning showed an ill-defined infiltration in the right lower lobe, with a very small pleural effusion in the same side consistent with recurrent pneumonia. However, it was not confirmed to be due to $S$. pneumoniae, because two pairs of blood cultures drown before the initiation of antibiotics were negative and a rapid urine antigen test for S. pneumoniae was not available. The patient presented a quick clinical improvement, and was discharged on the $7^{\text {th }}$ hospital day, without any rebound of his symptom until today.

\section{Discussion}

S. pneumoniae is the most common cause of communityacquired pneumonia. The burden of pneumococcal disease in HIV-seropositive patients is higher than that of the general population, with a 100 -fold risk for coexistence of pneumococcal pneumonia and bacteremia [1]. Among 9,283 adults aged 15-44 years old with a diagnosis of invasive pneumococcal disease (IPD), 2.4\% were living with undiagnosed HIV.

The incidence of IPD in any population is affected by geographic location, time of year, age, and vaccination status. Other predisposing factors include immunosuppression (e.g., HIV with low CD4 count and high levels of HIV RNA, syste- mic lupus erythematosus, multiple myeloma), social factors (e.g., alcohol abuse, injection drug use, homelessness, smoking), chronic conditions (e.g., cirrhosis, hypoalbuminemia, COPD, asthma, splenectomy, hyposplenism), previous episodes of pneumonia or influenza infection, and pregnancy [3-22].

Particularly in HIV patients, multiple immunity defects have been recognized, including $\mathrm{T}$ cells, $\mathrm{B}$ cells, low levels of IgG globulins against pneumococcal polysaccharide, and impairment of proinflammatory cytokines [23, 24]. Also, the pneumococcal serotypes may differ between HIV and non-HIV patients as highly invasive ones, such as 1, 5, and 7F, which have been shown to cause IPD to a much lower proportion to HIV patients than those with unknown HIV status [2]. The introduction of antiretroviral treatment (ART) has dramatically reduced the incidence of pneumococcal disease, with a further reduction attributed to the prophylaxis with trimethoprim-sulfamethoxazole against Pneumocystis jiroveci.

Although common sites of infection in the setting of S. pneumoniae bacteremia are the respiratory and/or central nervous system, alternative rare locations have also been described, as the gastrointestinal system [2].

The pathophysiology of streptococcal invasion to the gastrointestinal system have been attributed to: 1 ) direct invasion of the gut wall via hematogenous seeding; 2) direct infection via mucosal translocation; 3) enterotoxin production from S. pneumoniae strains stimulating a secretory diarrhea; 4 ) ascending invasion through the fallopian tubes in females [25].

To our knowledge (Table 1), this is the first case report on concurrent severe $S$. pneumoniae pneumonia and enteritis without any complaints from the respiratory system in a severely immunosuppressed patient in the last 26 years (1993-2018) [24-28], for the reasons discussed below. 
Due to the patient's CD4+ count $<100$ cells/ml, he was vulnerable to a plenty of causes, including opportunistic infections. There was no biopsy confirmation because he responded quickly to conservative treatment. Also, stool cultures lacked sensitivity for S. pneumoniae due to inhibitory culture media. Nevertheless, the patient's history, duration of symptoms, frequency, and the rest of laboratory tests were valuable in differential diagnosis.

It is evident that our patient suffered from bacteremic pneumonia and enteritis for the following reasons:

1. Pneumococcal bacteremia was documented in admission and symptoms of enteritis were prominent.

2. According to the duration of symptoms (less than four weeks), all the causes of chronic diarrhea (e.g., ART and HIV-related diarrhea) were excluded.

3. Fecal leucocytes in stool microscopy are not reported in pneumonia presenting with extrapulmonary symptoms [29].

4. No other pathogen was isolated from three stool samples (including parasites), and blood tests for CMV, HSV-1, HSV-2, and M. tuberculosis were negative.

5. Abdomen CT was consistent with enteritis.

6 . The patient's symptoms were related to the gastrointestinal (GI) system and resolved after the initiation of a short duration antibiotic treatment.

7. Disseminated atypical mycobacterial disease in a severely immunocompromised patient is a very serious persisting condition confirmed by positive blood cultures that demands a combination of antibiotics for an extended period of time to prevent recurrence.

8. There was no epidemiologic exposure history (travels, food, anal intercourses, etc.) leading to another diagnosis, but there are risk factors for streptococcal infection (smoking, immune defect) [25]. It is also noticeable that the patient was not vaccinated against pneumococcal bacteria as recommended, due to poor compliance. The importance of primary prophylaxis is emphasized by the fact that $61 \%$ of IPD episodes among HIV-positive adults are caused by serotypes covered by pneumococcal conjugate vaccine (PCV13) [30].

\section{Conclusions}

Invasive $S$. pneumonia disease may rarely present with predominant gastrointestinal symptoms. As a result, high suspicion for this entity should be held, when a patient with predisposing factors presents with GI symptoms [24, 31].

\section{References}

1. Frankel RE, Virata M, Hardalo C, Altice FL, Friedland G. Invasive pneumococcal disease: clinical features, serotypes, and antimicrobial resistance patterns in cases involving patients with and without human immunodeficiency virus infection. Clin Infect Dis 1996; 23 : 577-584.

2. Yin $Z$, Rice BD, Waight $P$, et al. Invasive pneumococcal disease among HIV-positive individuals, 2000-2009. AIDS 2012; 26: 87-94.

3. Centers for Disease Control and Prevention (CDC). Use of 13-valent pneumococcal conjugate vaccine and 23-valent pneumococcal polysaccharide vaccine among children aged 6-18 years with immunocompromising conditions: recommendations of the Advisory
Committee on Immunization Practices (ACIP). MMWR Morb Mortal Wkly Rep 2013; 62: 521-524.

4. Prevention of pneumococcal disease: recommendations of the Advisory Committee on Immunization Practices (ACIP). MMWR Recomm Rep 1997; 46(RR-8): 1-24.

5. Centers for Disease Control and Prevention (CDC). Advisory Committee on Immunization Practices. Pneumococcal vaccination for cochlear implant candidates and recipients: updated recommendations of the Advisory Committee on Immunization Practices. MMWR Morb Mortal Wkly Rep 2003; 52: 739-740.

6. Gentile JH, Sparo MD, Mercapide ME, Luna CM. Adult bacteremic pneumococcal pneumonia acquired in the community. A prospective study on 101 patients. Medicina (B Aires) 2003; 63: 9-14.

7. Laupland KB, Gregson DB, Zygun DA, Doig CJ, Mortis G, Church DL. Severe bloodstream infections: a population-based assessment. Crit Care Med 2004; 32: 992-997.

8. Talbot TR, Hartert TV, Mitchel E, et al. Asthma as a risk factor for invasive pneumococcal disease. N Engl J Med 2005; 352: 20822090.

9. Hargreaves RM, Lea JR, Griffiths H, et al. Immunological factors and risk of infection in plateau phase myeloma. J Clin Pathol 1995; 48: $260-266$

10. Twomey JJ. Infections complicating multiple myeloma and chronic lymphocytic leukemia. Arch Intern Med 1973; 132: 562-565.

11. Chi RC, Jackson LA, Neuzil KM. Characteristics and outcomes of older adults with community-acquired pneumococcal bacteremia. J Am Geriatr Soc 2006; 54: 115-120.

12. Romney MG, Hull MW, Gustafson R, et al. Large community outbreak of Streptococcus pneumoniae serotype 5 invasive infection in an impoverished, urban population. Clin Infect Dis 2008; 47: 768-774.

13. Nuorti JP, Butler JC, Farley MM, et al. Cigarette smoking and invasive pneumococcal disease. Active Bacterial Core Surveillance Team. N Engl J Med 2000; 342: 681-689.

14. Lipsky BA, Boyko EJ, Inui TS, Koepsell TD. Risk factors for acquiring pneumococcal infections. Arch Intern Med 1986; 146: 2179-2185.

15. Cruickshank HC, Jefferies JM, Clarke SC. Lifestyle risk factors for invasive pneumococcal disease: a systematic review. BMJ Open 2014; 4: e005224.

16. Kantsø B, Simonsen J, Hoffmann S, Valentiner-Branth P, Petersen AM, Jess T. Inflammatory bowel disease patients are at increased risk of invasive pneumococcal disease: a nationwide Danish cohort study 1977-2013. Am J Gastroenterol 2015; 110: 1582-1587.

17. Shigayeva A, Rudnick W, Green K, et al.; Toronto Invasive Bacterial Diseases Network. Invasive pneumococcal disease among immunocompromised persons: implications for vaccination programs. Clin Infect Dis 2016; 62: 139-147.

18. St Maurice A, Schaffner W, Griffin MR, Halasa N, Grijalva CG. Persistent sex disparities in invasive pneumococcal diseases in the conjugate vaccine era. J Infect Dis 2016; 214: 792-797.

19. Wiese AD, Griffin MR, Schaffner W, et al. Opioid analgesic use and risk for invasive pneumococcal diseases: a nested case-control study. Ann Intern Med 2018; 168: 396-404.

20. Tuomanen EI, Austrian R, Masure HR. Pathogenesis of pneumococcal infection. N Engl J Med 1995; 332: 1280-1284.

21. Ampofo K, Bender J, Sheng X, et al. Seasonal invasive pneumococcal disease in children: role of preceding respiratory viral infection. Pediatrics 2008; 122: 229-237.

22. Burgos J, Larrosa MN, Martinez A, et al. Impact of influenza season and environmental factors on the clinical presentation and outcome of invasive pneumococcal disease. Eur J Clin Microbiol Infect Dis 2015 ; 34 : 177-186.

23. Kantsø B, Green N, Goldblatt D, Benfield T. Antibody response is more likely to pneumococcal proteins than to polysaccharide after HIV-associated invasive pneumococcal disease. J Infect Dis 2015; 212: 1093-1099. 
24. Clark JA, Keroack MA. Pneumococcal appendicitis in a man with HIV infection. N Engl J Med 1993; 328: 1282.

25. Petti CA, Ignatius Ou SH, Sexton DJ. Acute terminal ileitis associated with pneumococcal bacteremia: case report and review of pneumococcal gastrointestinal diseases. Clin Infect Dis 2002; 34: E50-53.

26. Argemi X, Lefebvre N, Baldeyrou M, Douiri N, Hansmann Y. Streptococcus pneumoniae appendicitis and bacteremia in an immunocompetent adult. Med Mal Infect 2016; 46: 106-107.

27. Caierão J, Cornely AF, Da Cunha GR, Mott M, Zavascki AP, Dias C. Streptococcus pneumoniae appendicitis in an adult patient. Am J Emerg Med 2015; 33: 990.e1-3.

28. Ronnachit A, Ellenberger KA, Gray TJ, et al. Streptococcus pneumoniae causing intra-abdominal and pelvic infection: a case series. Cureus 2017; 9: e1967.

29. Emadi-Koochak H, Tabibian E, Rahimi-Dehgolan S. Abdominal pain as extrapulmonary presentation of pneumonia in an adult: a case report. Acta Medica Iranica 2017; 55: 131-133.

30. Crum-Cianflone NF, Wallace MR. Vaccination in HIV-infected adults. AIDS Patient Care and STDs 2014; 28: 397-410.

31. Harboe ZB, Larsen MV, Ladelund S, et al. Incidence and risk factors for invasive pneumococcal disease in HIV-infected and non-HIVinfected individuals before and after the introduction of combination antiretroviral therapy: persistent high risk among HIV-infected injecting drug users. Clin Infect Dis 2014; 59: 1168-1176.

32. Soman RN, Purandare BD, Rodrigues C, Rajwadkar-More V. Acute enteritis associated with pneumococcal bacteremia. J Assoc Physicians India 2009; 57: 173-174. 